Article

\title{
Genetic and Pathogenic Variability of Mycogone perniciosa Isolates Causing Wet Bubble Disease on Agaricus bisporus in China
}

\author{
Dan Li ${ }^{1,2,+}$, Frederick Leo Sossah ${ }^{1,2,+} \mathbb{D}$, Yang Yang ${ }^{1,2,+}$, Zhenghui Liu ${ }^{1}$, Yueting Dai ${ }^{1}$, \\ Bing Song ${ }^{1,2} \mathbb{D}$, Yongping $\mathrm{Fu}^{1,2, *}$ and $\mathrm{Yu} \mathrm{Li}^{1,2}$ \\ 1 Engineering Research Center of Chinese Ministry of Education for Edible and Medicinal Fungi, \\ Jilin Agricultural University, Changchun 130118, China; lidan@jlau.edu.cn (D.L.); \\ flsossah@jlau.edu.cn (F.L.S.); 2015yangyang@jlau.edu.cn (Y.Y.); liuzhenghui@jlau.edu.cn (Z.L.); \\ daiyueting18@jlau.edu.cn (Y.D.); song19800123@jlau.edu.cn (B.S.); liyu@jlau.edu.cn (Y.L.) \\ 2 School of Plant Protection, Jilin Agricultural University, Changchun 130118, China \\ * Correspondence: fuyongping@jlau.edu.cn \\ + These authors contributed equally to this work.
}

Received: 3 September 2019; Accepted: 1 October 2019; Published: 8 October 2019

\begin{abstract}
Wet bubble disease, caused by Mycogone perniciosa, is a major threat to Agaricus bisporus production in China. In order to understand the variability in genetic, pathogenicity, morphology, and symptom production of the fungus, 18 isolates of the pathogen were collected from diseased A. bisporus in different provinces in China. The isolates were characterized by a combination of morphological, cultural, molecular, and pathogenicity testing on different strains of $A$. bisporus and amplified fragment length polymorphism (AFLP) analysis. The 18 isolates were identified by Koch's postulate and confirmed different pathogenic variability among them. The yellow to brown isolates were more virulent than the white isolates. AFLP markers clustered the isolates into two distinct groups based on their colony color, with a high level of polymorphism of Jaccard similarities range from $0.39 \%$ to $0.64 \%$. However, there was no evidence of an association between the genetic diversity and the geographical origin of the isolates. Through knowledge of the genetic diversity, phenotypic virulence of $M$. perniciosa is a key factor for successful breeding of resistant strains of $A$. bisporus and developing of an integrated disease management strategy to manage wet bubble disease of A. bisporus.
\end{abstract}

Keywords: AFLP; Mycogone perniciosa; wet bubble disease; pathogenicity; diversity

\section{Introduction}

Agaricus bisporus (Lange) Imbach, the button mushroom, is an edible and medicinal basidiomycete that belongs to the family Agaricaceae. It is widely distributed, and one of the most cultivated and consumed mushrooms in the world. China is one of the largest producers of A. bisporus in the world [1]. The global demand for healthy and nutritious food has led to the continuous expansion of the cultivation area by indigenous farmers and industrial factories in China [2]. However, the production of $A$. bisporus is severely constrained by diseases such as Mycogone perniciosa, the causal agent of wet bubble disease [3]. Wet bubble disease causes significant economic losses in button mushroom worldwide [4,5]. In China, yield losses of about $15-30 \%$ are due to the occurrence of this disease, while rapid epidemics or severe infections can lead to total mushroom loss [6].

Mycogone perniciosa can cause a wide range of symptom severity during infection and the disease is usually controlled by cultural practices coupled with the application of fungicides [3]. However, none of the present control measures have been found completely effective due to resistance development to 
fungicides [3,6]. The resistance of some commercial and wild strains of A. bisporus to M. perniciosa is known [7]. However, genes governing resistance have not yet been identified. In addition, there is variability in the morphological traits (appearance, growth rate, colony color), and pathogenicity of M. perniciosa isolates [4].

During the past few decades, the molecular methods widely used to evaluate the genetic diversity among $M$. perniciosa isolates include restriction fragment length polymorphism (RFLP) [4], random amplified polymorphic DNA (RAPD) [7], inter-simple sequence repeats (ISSR) [8], sequence-related amplification polymorphism (SRAP) [9], and sequence-characterized amplified region (SCAR) markers [10]. Compared to the above molecular methods, the amplified fragment length polymorphism (AFLP) provides a higher resolution, higher efficiency in detecting polymorphism, more reliable, reproducible, and easily transferable to other markers such as simple sequence repeats (SSR) [11]. Hence, it is mainly applied to genetic variability and population biology studies. Previous work by several authors [7-10] using RFLP, SRAP, ISSR, and SCAR markers shows the existence of high genetic variability in M. perniciosa isolates. Despite the severe economic losses caused by wet bubble disease in China, there is limited information about the genetic and pathogenic diversity of M. perniciosa isolates in the country and whether the wide variation in virulence is associated with the phenotype or geographical origin of the isolates.

The aim of the present study was to (1) characterize 18 isolates of M. perniciosa producing wet bubble disease symptoms on A. bisporus in four different provinces in China using morphological and cultural characters and phylogenetic analysis of the internal transcribed spacer (ITS) region of the ribosomal DNA, and (2) assess the pathogenic variability on six A. bisporus strains and estimated the genetic diversity using AFLP markers.

\section{Results}

\subsection{Morphological Characterization and Phylogenetic Analyses of Mycogone perniciosa}

Fungal isolates were collected from infected A. bisporus basidiome showing symptoms of wet bubble disease from different provinces (Gansu, Fujian, Shandong, and Hubei) of China (Table 1). Eighteen isolates were initially identified as M. perniciosa on the basis of colony morphology and microscopic observations. The mycelia color of the isolates ranged from white to dark brown [4] on PDA for seven days at $25{ }^{\circ} \mathrm{C}$ (Figure 1). The colony texture was either villous or concentric circles, with all white-colored colonies having villous texture. The average colony growth rates (colonies were 7.1 to $18 \mathrm{~mm}$ in diameter) was $11.73 \mathrm{~mm} /$ day. The spores of M. perniciosa in the anamorph stage are divided into two types: one is the conidia with thin cell wall, ellipse, colorless and transparent, which are born on the conidia pedicel with a diameter of $9.77 \times 4.25 \mu \mathrm{m}-12.77 \times 6.05 \mu \mathrm{m}$ (averge, $\mathrm{n}=60$ ) and the other one is the chlamydospore composed of the upper and lower cells. The upper cell is yellow-brown to gray-brown, and the lower cell is colorless and transparent, its size is from $11.36 \times 8.08 \mu \mathrm{m}-33.43 \times 25.94 \mu \mathrm{m}$ (averge, $\mathrm{n}=60$ ).

On PDA chlamydospores were not observed on $\mathrm{Hp} 2$ and $\mathrm{Hp} 9$, similarly, conidia were not observed for H2, Hp8, and Hp9 (Supplementary Table S1). The isolates with brown colony morphology produced more conidia compared to the isolates with white colony morphology. The cultural and morphological characteristics of all isolates were consistent with those of the genus M. perniciosa (Magn.) Delacroix (teleomorph $=$ Hypomyces perniciosus Magnus) [4]. The sequencing of the amplified PCR product of the ITS gene for the isolates resulted in an amplicon size of $750 \mathrm{bp}$. Blast search of the sequences of the individual isolates revealed a 99\% homology to M. perniciosa sequences at the NCBI GenBank database. All of the 18 isolates of M. perniciosa were pathogenic on A. bisporus strain CCMJ1020 resulting in brown spot, malformation, and water-soaking symptoms typical for wet bubble disease. The M. perniciosa inoculated button mushrooms showed symptoms similar to those observed in the field (Figure 2) and the fungi were consistently re-isolated but not from controls, thus fulfilling Koch's postulate, while the controls exhibited no symptoms. Based on the colony morphology, cultural characteristics, 
and phylogenetic analysis [9], and the pathogen was identified as M. perniciosa (Magn.) Delacroix. All resulting sequences were deposited in NCBI GenBank; accession numbers are shown in Table 1.
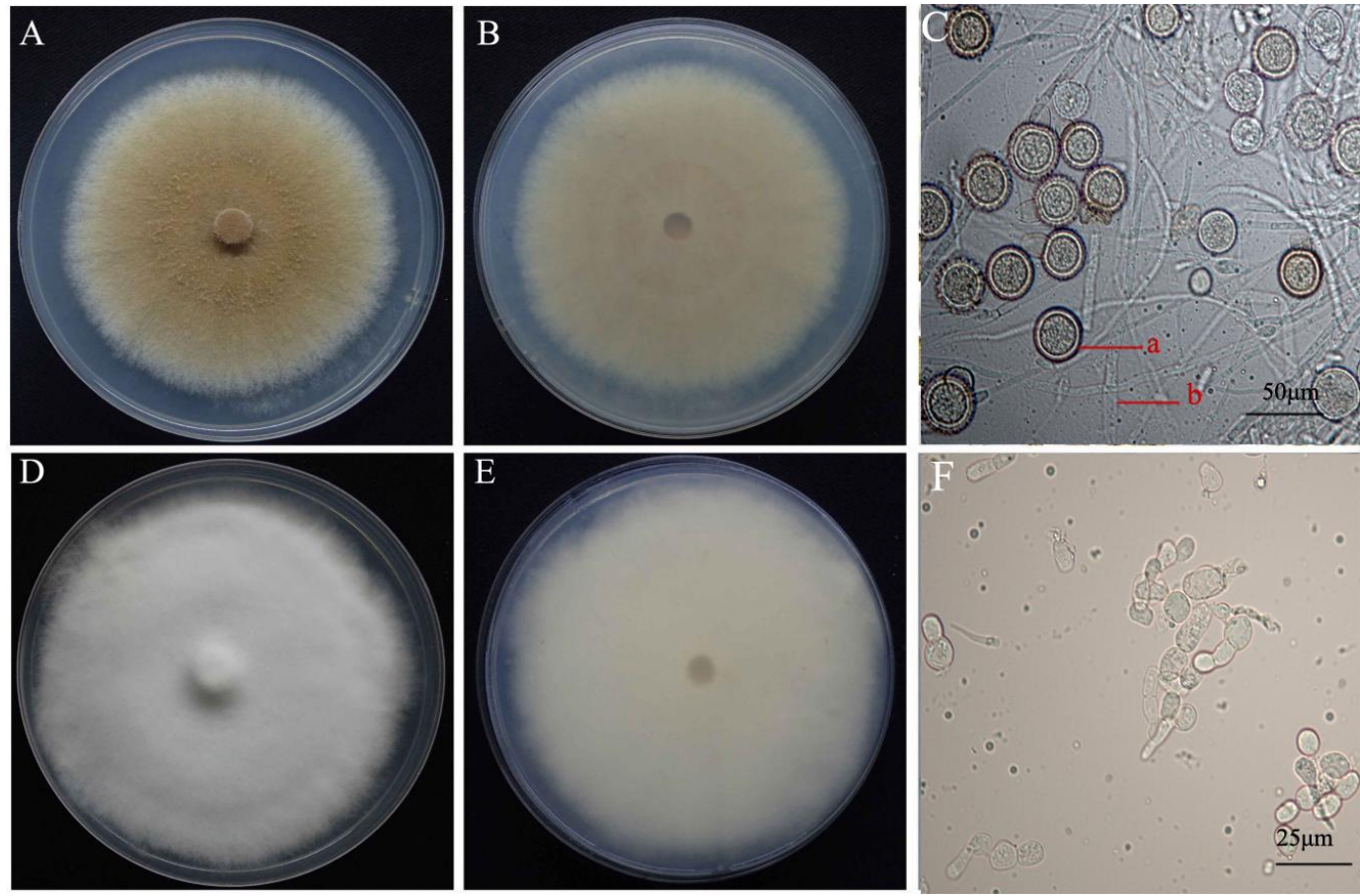

Figure 1. Colony morphology and microscopic characteristics of Mycogone perniciosa: colony color. (A) upper, (B) under, (C) microstructure for isolate HP10. Colony color (D) upper, (E) under, (F) microstructure for isolate Hp2. (a) aleuriospore; (b) hypha.
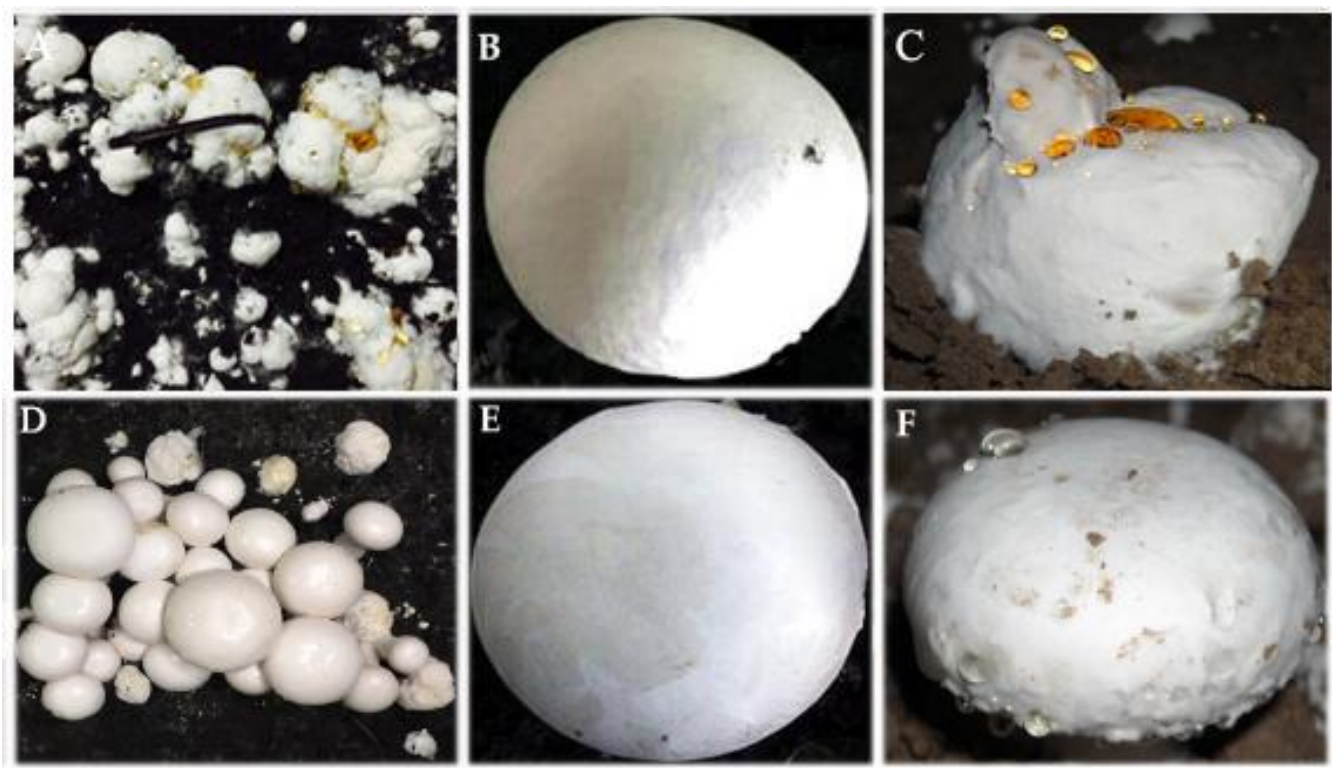

Figure 2. Pathogenicity tests for Mycogone perniciosa on Agaricus bisporus strain CCMJ1020: isolate Hp10. (A) Diseased basidiome occurring in the field, (B) Control, (C) wet bubble disease from pathogenicity test. Isolate Hp2 (D) Diseased basidiome occurring in the field, (E) control, (F) wet bubble disease from pathogenicity test. 
Table 1. Morphological characteristics of 18 isolates of Mycogone perniciosa growing on PDA medium at $25^{\circ} \mathrm{C}$ for 7 days.

\begin{tabular}{|c|c|c|c|c|c|c|c|c|c|c|c|c|c|c|}
\hline \multirow{3}{*}{ No } & \multirow{3}{*}{ Isolates } & \multirow{3}{*}{$\begin{array}{c}\text { Origin } \\
\text { Locality }\end{array}$} & \multicolumn{3}{|c|}{ Colony } & \multicolumn{8}{|c|}{ Conidia } & \multirow{3}{*}{$\begin{array}{c}\begin{array}{c}\text { GenBank } \\
\text { Accession No }\end{array} \\
\text { ITS }\end{array}$} \\
\hline & & & \multirow[b]{2}{*}{ Texture } & \multirow[b]{2}{*}{ Growth $(\mathrm{mm} / \mathrm{d})$} & \multirow[b]{2}{*}{ Color } & \multicolumn{4}{|c|}{ Chlamydospore } & \multicolumn{4}{|c|}{ Conidium } & \\
\hline & & & & & & Color & Shape & $\begin{array}{c}\text { Length } \\
(\mu \mathrm{m})\end{array}$ & $\begin{array}{l}\text { Width } \\
(\mu \mathrm{m})\end{array}$ & Color & Shape & $\begin{array}{l}\text { Length } \\
(\mu \mathrm{m})\end{array}$ & $\begin{array}{c}\text { Width } \\
(\mu \mathrm{m})\end{array}$ & \\
\hline 1 & Hp1 & Gansu & Villous & 7.1 & White & light brown & ellipsoid & $6.5-25.1$ & $4.5-15$ & Colorless & cylinder, rhabditiform & $6.7-25.8$ & $2.5-7.8$ & MK583555 \\
\hline 2 & Hр2 & Gansu & Villous & 7.6 & White & - & - & - & - & - & - & - & - & MK584644 \\
\hline 3 & Нp3 & Fujian & Villous & 12.6 & White & brown & Pear-Shaped & $24-44$ & $14-28$ & Colorless & cylinder, rhabditiform & $5.9-17.7$ & $2.9-8$ & MK584650 \\
\hline 4 & Hp4 & Fujian & Villous & 12.7 & White & brown & Pear-Shaped & $24-42$ & $14-38$ & Colorless & cylinder, rhabditiform & $9-30$ & 3-11 & MK583561 \\
\hline 5 & Hp5 & Fujian & Villous & 12 & White & light brown & ellipsoid & $13.6-30.6$ & $7.8-19.4$ & Colorless & cylinder, rhabditiform & $5.4-16.9$ & $3.1-10.7$ & MK583565 \\
\hline 6 & Hp6 & Shandong & Concentric circles & 10.4 & brown & brown & Pear-Shaped & $24-48$ & $15-30$ & Colorless & cylinder, rhabditiform & $7-17$ & $2-7.5$ & MK584645 \\
\hline 7 & Hp7 & Fujian & Concentric circles & 12 & brown & brown & Pear-Shaped & $18-42.5$ & $13.7-27.7$ & Colorless & cylinder, rhabditiform & $8-17.2$ & $2.8-7.6$ & MK583576 \\
\hline 8 & Hp8 & Shandong & Concentric circles & 9.7 & brown & - & - & - & - & - & - & - & - & MK584648 \\
\hline 9 & Hp9 & Gansu & Villous & 9.4 & brown & brown & Pear-Shaped & $18.4-35.4$ & $12-27.7$ & - & - & - & - & MK584651 \\
\hline 10 & Hp10 & Hubei & Concentric circles & 12 & brown & brown & Pear-Shaped & $25.5-40.5$ & 14-32 & Colorless & cylinder, rhabditiform & $8.3-24$ & $2-8$ & MK584647 \\
\hline 11 & Hp11 & Shandong & Concentric circles & 12.7 & brown & light brown & ellipsoid & $17.2-35.7$ & $10-30$ & Colorless & cylinder, rhabditiform & $7.8-20$ & $3-8.6$ & MK584649 \\
\hline 12 & Hp12 & Shandong & Concentric circles & 11.1 & brown & brown & Pear-Shaped & $26.2-41.6$ & $19.8-28$ & Colorless & cylinder, rhabditiform & $5.2-17.6$ & $3.2-7.6$ & MK584646 \\
\hline 13 & Hp13 & Fujian & Concentric circles & 14 & brown & brown & Pear-Shaped & $20-36$ & $10-25$ & Colorless & cylinder, rhabditiform & $6.7-18$ & $2.5-5.2$ & MK584655 \\
\hline 14 & Hp14 & Fujian & Concentric circles & 15 & brown & light brown & ellipsoid & $19-35.3$ & $12-25$ & Colorless & cylinder, rhabditiform & 6-18 & $4.6-6$ & MK584656 \\
\hline 15 & Hp15 & Shandong & Concentric circles & 12.5 & brown & brown & Pear-Shaped & $21-35$ & $17.1-28$ & Colorless & cylinder, rhabditiform & $8.8-20.7$ & $3.1-12$ & MK584652 \\
\hline 16 & Hp16 & Fujian & Concentric circles & 11.6 & brown & light brown & ellipsoid & $9.9-43.5$ & $5.5-31$ & Colorless & cylinder, rhabditiform & $6.5-20$ & $2.8-5.8$ & MK584653 \\
\hline 17 & Hp17 & Fujian & Concentric circles & 12.5 & brown & brown & Pear-Shaped & $25-42$ & $18.8-30$ & Colorless & cylinder, rhabditiform & $5-16$ & $2-5.8$ & MK584654 \\
\hline 18 & Hp18 & Fujian & Concentric circles & 14.2 & brown & brown & Pear-Shaped & $23-41$ & $23-27$ & Colorless & cylinder, rhabditiform & $6.6-21.6$ & $1.9-6.5$ & MK583447 \\
\hline
\end{tabular}




\subsection{Pathogenicity Variability}

The A. bisporus strains expressed wet bubble disease symptoms $2-5$ days post-inoculation of M. perniciosa isolates using a concentration of $1 \times 10^{5}$ conidial suspension. The minimum incubation period was 2-3 days for all isolates on the highly susceptible $A$. bisporus strains and those for highly resistant $A$. bisporus strains required a maximum incubation period of five days. The wet bubble disease symptoms on A. bisporus include malformation of basidiome, white, fluffy mycelial growth, copious amber droplets, and flocculent mycelia on most substrates [12]. All the isolates produced typical wet bubble disease symptoms with different levels of symptom severity depending on all the A. bisporus strains tested. There was a constant increase in the symptom severity scores from seven to 30 days post-inoculation during disease progression. Out of the 18 isolates caused disease on all the tested A. bisporus cultivars and had a severity score of more than $50 \%$. Seven did not produce any visible symptoms on A. bisporus strain CCMJ1110. The most virulent isolate was Hp10 collected from Hubei province. Most of the isolates with lower virulence levels were those with white colony morphology. The least virulent isolate was Hp1 collected from Gansu province (see Table 2).

Table 2. Pathogenic variability of Mycogone perniciosa isolates on different Agaricus bisporus strains.

\begin{tabular}{|c|c|c|c|c|c|c|}
\hline \multirow{2}{*}{${ }^{1}$ M. perniciosa Isolates } & \multicolumn{6}{|c|}{${ }^{2}$ Different Agaricus bisporus Strains } \\
\hline & CCMJ1020 & CCMJ1053 & CCMJ1036 & CСMJ1074 & CСMJ1106 & CCMJ1110 \\
\hline Hp1 & $S$ & $\mathrm{R}$ & $\mathrm{R}$ & $\mathrm{R}$ & $\mathrm{R}$ & $\mathrm{R}$ \\
\hline $\mathrm{Hp} 2$ & $\mathrm{~S}$ & $S$ & $\mathrm{R}$ & $S$ & $\mathrm{R}$ & $\mathrm{R}$ \\
\hline $\mathrm{Hp} 3$ & $S$ & S & S & S & $\mathrm{R}$ & $\mathrm{R}$ \\
\hline $\mathrm{Hp} 4$ & $S$ & $S$ & $\mathrm{R}$ & $S$ & $\mathrm{R}$ & $\mathrm{R}$ \\
\hline Hp5 & $S$ & $S$ & $\mathrm{R}$ & $\mathrm{R}$ & $\mathrm{R}$ & $\mathrm{R}$ \\
\hline Hp6 & $S$ & $S$ & $\mathrm{R}$ & $S$ & $\mathrm{R}$ & $\mathrm{R}$ \\
\hline $\mathrm{Hp} 7$ & $S$ & $\mathrm{R}$ & $\mathrm{R}$ & $\mathrm{R}$ & $\mathrm{R}$ & $\mathrm{R}$ \\
\hline Hp8 & $S$ & $\mathrm{R}$ & $S$ & $\mathrm{R}$ & $\mathrm{R}$ & $\mathrm{R}$ \\
\hline $\mathrm{Hp} 9$ & $S$ & $\mathrm{R}$ & $\mathrm{R}$ & $\mathrm{R}$ & $\mathrm{R}$ & $\mathrm{R}$ \\
\hline Hp10 & $S$ & $S$ & $S$ & $S$ & $S$ & $S$ \\
\hline Hp11 & $S$ & $\mathrm{R}$ & $S$ & $\mathrm{R}$ & $\mathrm{R}$ & $\mathrm{R}$ \\
\hline Hp12 & $S$ & $\mathrm{R}$ & $S$ & $S$ & $S$ & $S$ \\
\hline Hp13 & $S$ & $S$ & $\mathrm{R}$ & $S$ & $\mathrm{R}$ & $\mathrm{R}$ \\
\hline Hp14 & $S$ & $S$ & $\mathrm{R}$ & $\mathrm{R}$ & $S$ & $\mathrm{R}$ \\
\hline Hp15 & $S$ & $\mathrm{R}$ & $S$ & $\mathrm{R}$ & $\mathrm{R}$ & $\mathrm{R}$ \\
\hline Hp16 & $\mathrm{S}$ & $\mathrm{S}$ & $\mathrm{R}$ & $\mathrm{R}$ & $\mathrm{R}$ & $\mathrm{R}$ \\
\hline Hp17 & $S$ & $S$ & $\mathrm{R}$ & $\mathrm{R}$ & $S$ & $\mathrm{R}$ \\
\hline Hp18 & $S$ & $S$ & $\mathrm{R}$ & $\mathrm{R}$ & $\mathrm{R}$ & $\mathrm{R}$ \\
\hline
\end{tabular}

${ }^{1}$ M. perniciosa isolates with different pathogenic variability. ${ }^{2}$ A. bisporus strains were classified as resistant $(\mathrm{R})$ or susceptible (S) to M. perniciosa based on visual disease scores.

\subsection{AFLP Analysis}

The M. perniciosa AFLP fingerprints produced a total of 1221 scorable loci from the combination of 10 primer pairs. The number of bands generated per isolate ranged from a minimum of 108 bands by primer D-2 to a maximum of 130 bands by primer pairs B- 1 and B-8. The analysis revealed a total of 1206 (98.8\%) polymorphic AFLP fragments ranging in size from $69.5 \mathrm{bp}$ to $499.7 \mathrm{bp}$. The AFLP experiment was repeated three times and all the polymorphic DNA fragments were identical. The dendrogram (Figure 3) for the 18 isolates were drawn from the genetic similarity data using the UPGMA method with the Jaccard's pairwise similarity coefficients. The isolates clustered into two well-defined distinct groups with a mean similarity coefficient of 0.39 . The isolates were not clustered based on their geographic location. Cluster A $(s=0.495-0.6)$ grouped five isolates, two collected from Gansu (Hp1 and $\mathrm{Hp} 2)$ and three from Fujian (Hp3-Hp5) provinces of China. The isolates from cluster A were all pathogenic to the susceptible A. bisporus strains (CCMJ1020). None of the isolates in this cluster was pathogenic on the resistant $A$. bisporus (CCMJ1106 and CCMJ1110) strains. In addition, they caused mild forms of wet bubble disease on A. bisporus strains. Thirteen isolates were grouped into cluster B ( $s=0.46-0.64)$ and they were collected from Fujian, Gansu, Shandong, and Hubei. The isolates in 
cluster B were yellow to brown and they caused the severe forms of wet bubble disease on A. bisporus. Within the clusters, the isolates showed a high degree of variability, however, isolates Hp11 and Hp 12 in cluster B showed the greatest similarity at 0.64 (Figures 3 and 4).

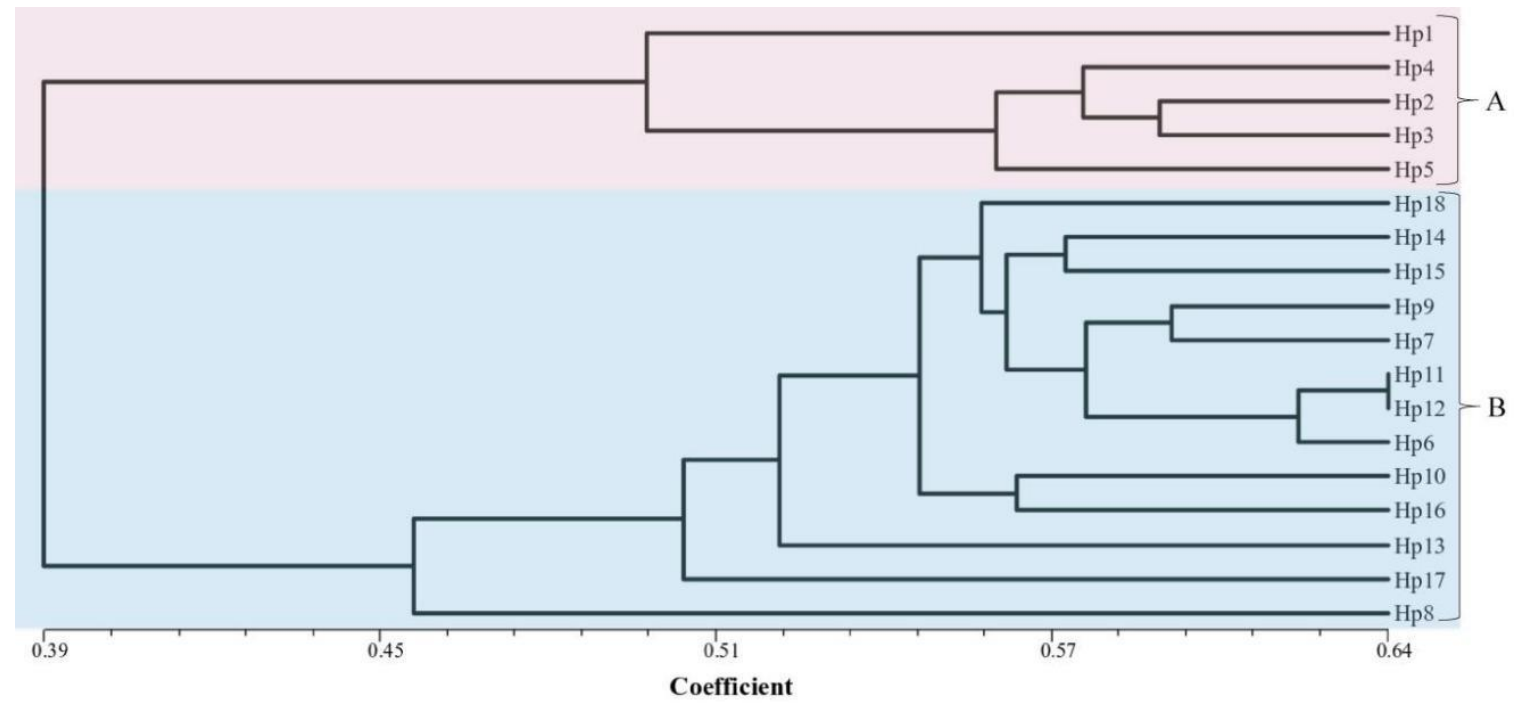

Figure 3. UPGMA (unweighted pair group method with arithmetic mean) dendrogram of Mycogone perniciosa isolates based on the genetic similarity matrix obtained with the Jaccard index for the data from AFLP markers.
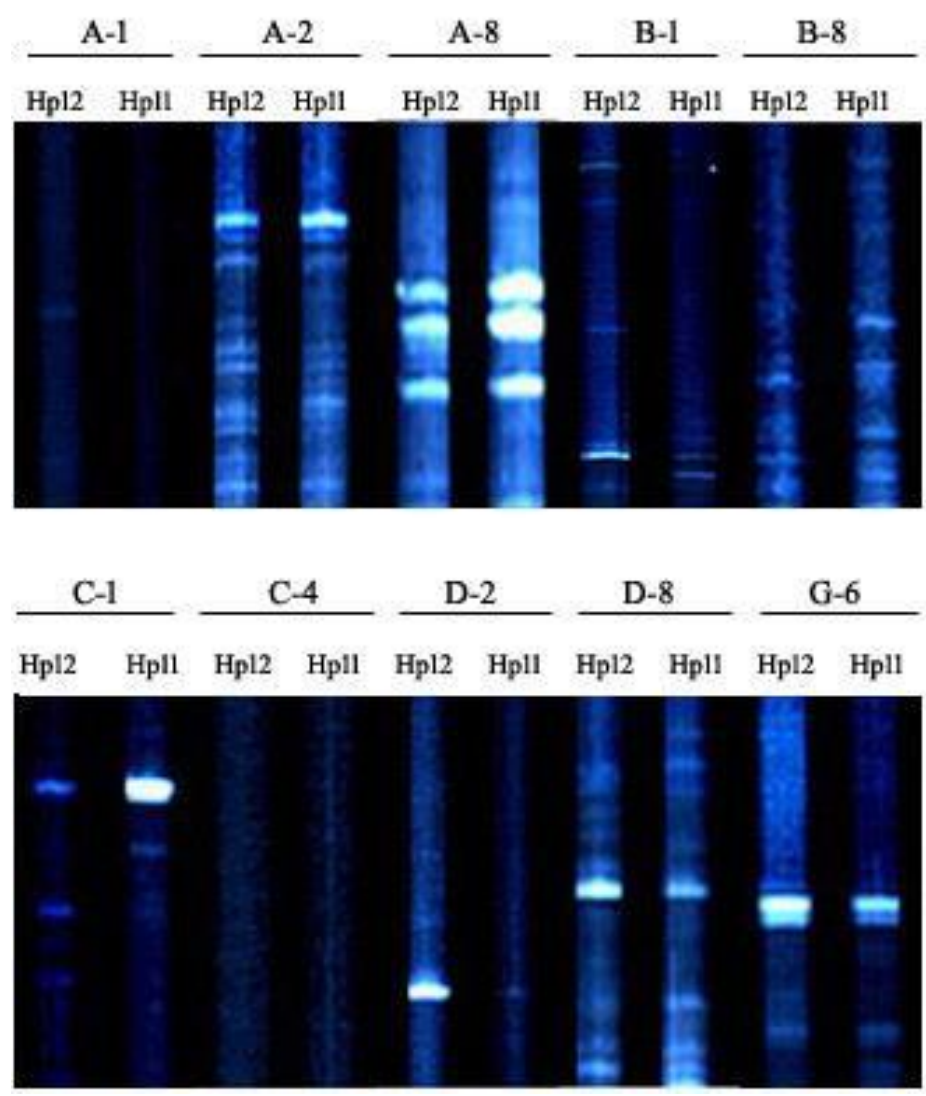

Figure 4. Gel image showing the AFLP banding pattern of Hp11 and Hp 12 of Mycogone perniciosa. 


\section{Discussion}

Mycogone perniciosa is a recurrent pathogen causing substantial yield losses on diverse edible mushrooms (A. bisporus, Pleurotus ostreatus, P. citrinopileatus, Volvariella volvacea, etc.) $[4,13]$ during severe epidemics globally. In this study, we investigated the genetic variability and pathogenicity (virulence) of M. perniciosa from major Agaricus bisporus growing areas in China. Eighteen isolates of M. perniciosa causing wet bubble disease on A. bisporus in Fujian, Hubei, Gansu, and Shandong were identified based on their colony morpho-cultural characters and confirmed by molecular characterization using ITS region and pathogenicity testing on A. bisporus strain CCMJ1020 [3,7,14]. The subunits of ribosomal DNA (rDNA) genes have been widely used in fungal identification [15]. Consequently, the results indicate the importance of a combination of molecular and morphological data for unambiguous identification of fungal species [16]. The inoculation of M. perniciosa isolates on the six different A. bisporus strains, the consequential incubation period and wet bubble disease development showed the variation in their pathogenicity and virulence. The M. perniciosa isolates were low, moderate, and highly virulent based on their symptom development and the number of different $A$. bisporus. The white, yellow, and brown white isolates produced mild, moderate, and severe symptoms with corresponding increasing disease severity scores. The brown isolate (Hp 10) had the highest virulence level, which caused disease on all the different strains of $A$. bisporus. The variability in virulence of isolates indicates that there must be different pathotypes in $M$. perniciosa populations, therefore, it requires proper pathogenicity test on different strains of $A$. bisporus to clearly distinguish the pathogenic variability.

Isolates (Hp2, Hp8, and Hp9) of M. perniciosa did not produce conidia, so the mycelial suspension was used as inoculum for pathogenicity testing. From our analysis, we could not determine the extent to which this type of primary inoculum might have influenced the results of the virulence level of the isolates [17]. Fletcher et al. [4] also used symptom severity to characterize the virulence of M. perniciosa. The severity of disease symptoms is dependent on the isolate, spore inoculum and the host tolerance levels to the pathogen [18]. The white isolates of $M$. perniciosa showed less pathogenicity compared to the yellow/brown isolates. This may be due to the colorless conidia and a lower degree of sporulation compared to the yellow/brown colonies. For example, Fletcher et al. [4] reported that non-pigmented white isolates of $M$. perniciosa are less pathogenic than the pigmented isolates. The moderate to high virulence levels of the yellow to brown M. perniciosa isolates may be due to a large amount of conidia production, and production of secondary metabolites (e.g., pigments and mycotoxins) plays an important role in pathogenesis [12,19]. In contrast, Fletcher et al. [4] reported that the less aggressiveness of some of the isolates maybe as a result of mycovirus infecting those strains. However, in this study, we did not test the presence of virus-like particles in any of the isolates. In addition, coevolution of a pathogen and host, host adaptation or response to the pathogen may lead to variation in virulence or virulent pathotypes [20-22].

AFLP analysis was used to infer the genetic variability of the $18 \mathrm{M}$. perniciosa isolates. The results reveal high genetic diversity among the isolates. The genetic diversity observed using AFLP is higher than those conducted in China using SRAP, and RAPD, ISSR, SRAP, and SCAR marker respectively [7-10]. Although it is difficult to compare levels of genetic diversity obtained with different markers and different sample sizes [23]. The AFLP technique has been shown to be a very powerful method for genetic diversity studies, because it detects many polymorphisms in a single assay, shows reasonable coverage of the genome, and is highly repeatable [24]. The application of AFLP fingerprinting was sensitive enough to distinguish between the isolates, thus provides a powerful tool for distinguishing inter- and intra-species [25]. The variability in the morphological and cultural characteristics of the isolates was supported by the AFLP analysis. The isolates were clustered into two groups based on their morphology; however, there was no correlation between the clustering and their geographical origin. This may be due to the large diversity of the pathogen population in China. Variations in cultural characteristics have been observed in the isolates of M. perniciosa [4]). The AFLP data showed that Hp11 and Hp 12 were genetically similar (Figure 4). Though both isolates were 
collected from Shandong province, they were isolated from different cities. This could be due to the exchange of $A$. bisporus material from different locations.

Mutation, gene flow, sexual reproduction (recombination) and the adaptation to diverse fungal hosts might have contributed to the genetic diversity of M. perniciosa from the AFLP analysis. In our previous work [12], the analysis of the genome sequence of M. perniciosa ( $\mathrm{Hp} \mathrm{10)} \mathrm{revealed} \mathrm{it} \mathrm{is}$ heterothallic species containing MAT 1-2 locus. There is a need for further studies to identify the sexual stages of the isolates to find out whether the sexual stage contributes to the diversity of this pathogen [26]. In addition, the diversity of host germplasm, cultivation method of A. bisporus, or environmental factors may play a role in determining the diversity of the pathogen.

\section{Materials and Methods}

\subsection{Fungal Isolates and Morphological Characteristics}

Mycogone perniciosa isolates (Table 1) were obtained from the fruiting bodies of A. bisporus showing typical symptoms of wet bubbled disease in mushroom farms located in Fujian, Gansu, Hubei, and Shandong provinces of China. The disease survey was carried out in 2014-2015. The sampled infected tissues were sterilized in $2 \%$ sodium hypochlorite $(\mathrm{NaClO})$ solution for 60 secs and washed three times with sterilized deionized (DI) water, then plated on Petri dishes containing PDA (potatoes $200 \mathrm{~g} / \mathrm{L}$, glucose $20 \mathrm{~g} / \mathrm{L}$, agar $15 \mathrm{~g} / \mathrm{L}$ ) amended with $100 \mathrm{mg} / \mathrm{L}$ Kanamycin and incubated at $25^{\circ} \mathrm{C}$ for 5 days in darkness. Pure cultures were subsequently obtained through single spore isolation from all colonies showing the morphological characteristic of a typical M. perniciosa and five representative purified isolates sub-cultured on PDA without antibiotics. The growth characteristics, colony morphology, and conidial characteristics-such as shape, length, width-were examined for a total of 18 representative isolates. Colony color was assessed 7-10 days after single spores were transferred to PDA. A minimum of 30 conidial characters was observed under a Leica DMR HC microscope (Leica Microsystems Imaging Solutions Ltd., Cambridge, UK) fitted with Leica DFC320. The sporulation of the isolates was estimated as described by Santos et al. [27]. Briefly, $100 \mathrm{mg}$ of the fungal mycelium of each isolate was collected and transferred to an Eppendorf tube, in which it was homogenized with $1 \mathrm{~mL}$ of Tween 80 solution $(0.05 \%)$. The conidia count of each such suspension was then determined using a Neubauer chamber. Conidia counts were performed in triplicate for each isolate. All cultures were conserved on PDA in slant tubes and deposited in the Engineering Research Center of the Chinese Ministry of Education for Edible and Medicinal Fungi of Jilin Agricultural University (HMJAU) in China.

\subsection{DNA Extraction and Molecular Identification}

Total genomic DNA was extracted from 7-day old mycelia mat growing on PDA plates with cellophane sheets using the Nuclear Plant Genomic DNA Kit of CWBIO (CWBIOTECH, Beijing) following the manufacturer's protocol. The DNA quality and quantity were measured using a BioSpec-nano spectrophotometer (Shimadzu Biotech, Tokyo, Japan) at a wavelength of 260 and 280 $\mathrm{nm}$, respectively. The DNA was stored at $-80^{\circ} \mathrm{C}$ until required for further use.

PCR amplification and sequencing of the internal transcribed spacer regions of the rDNA was performed for each isolate utilizing the primer set ITS4 and ITS5 [28]. The obtained sequences were individually checked by BLAST analysis against the NCBI GenBank (http://www.ncbi.nlm.nih.gov/) database and highly corresponding sequences were retrieved, aligned, and the phylogenetic tree constructed with the maximum likelihood method using the Tamura and Nei substitution method [29] in MEGAX [30]. 


\subsection{Pathogenicity Tests}

\subsubsection{Mushroom Strains and Cultivation Method}

Pathogenicity and virulence were carried out at the Mushroom Base of Jilin Agricultural University, Changchun, China from September 2015 to March 2017. The pathogens were tested on six different strains of A. bisporus with known different level of disease resistance [7] to M. perniciosa (highly susceptible (CCMJ1020, CCMJ1036) moderately resistant (CCMJ1053, CCMJ1074) and highly resistant (CCMJ1106, CCMJ1110) collected from the Herbarium of the Institute of Mycological, Jilin Agricultural University, China). The A. bisporus strains were grown in baskets with dimensions $(45 \times 33 \times 25 \mathrm{~cm})$ filled with $7.5 \mathrm{~kg}$ of compost. About $4 \mathrm{~cm}$ thick casing soil was applied to cover the compost when the mycelium overgrew the compost. To induce fruiting, the room temperature was set at $21-24{ }^{\circ} \mathrm{C}$, relative humidity control to $80-95 \%$, and the $\mathrm{CO}_{2}$ concentration was in $1200-1500 \mathrm{ppm}$.

\subsubsection{Inoculum Preparation and Disease Assessment}

The inoculum for each M. perniciosa isolates was prepared from 7-day old cultures on PDA, by washing down the pathogen conidia with sterile distilled water and sieving the deferment via six layers of sterile cheesecloth. The spore/conidial concentration was estimated using a hemocytometer. The optimal spore/conidial concentration of the suspension for the isolates to cause disease was determined by inoculating $10^{4}, 10^{5}, 5 \times 10^{5}$, and $10^{6}$ conidia/ml suspension on A. bisporus strains CCMJ1020 and CCMJ1036. A spore/conidial concentration of $1 \times 10^{5}$ was standardized and used for disease inoculation for all the A. bisporus strains.

Three days after the application of casing soil and regulation of temperature and relative humidity, approximately $50 \mathrm{ml}$ of inoculum (spore/ conidial concentration $10^{5} / \mathrm{ml}$ ) were sprayed into each basket containing the cultivated button mushroom. The controls were sprayed with $50 \mathrm{ml}$ of sterile distilled water. Three replications were evaluated per isolate per mushroom strain. Disease assessment was recorded for the first flush. Pathogenicity was determined by the number of $A$. bisporus strains on which an isolate caused wet bubble disease and the order of susceptibility of strains to individual isolates. Pathogenicity tests to confirm Koch's postulate was assessed on A. bisporus strain CCMJ1020. Disease severity was rated on sporocarp of individual mushroom strains for 30 days after inoculation using a $0-5$ visual rating scale, where $0=$ no symptom; $1=1-10 \% ; 2=11-25 \% ; 3=26-50 \% ; 4=51-75 \%$; and $5=>75 \%$ based on the number of sporocarp showing disease against the total mushrooms harvested from the baskets. Based on the rating scale, the A. bisporus strains were classified as either resistant or susceptible ( $\leq 3=$ resistance $(\mathrm{R})$ and $>3=$ susceptible $(S))$. The severity indexes were subjected to one-way analysis of variance, and significant mean differences $(P=0.05)$ were determined with Duncan's multiple range test using GenStat 12th Edition version 12.0.0.3033 (VSNI, Hemel Hempstead, England). The experiment was repeated three times in a completely randomized design with three replicates per M. perniciosa isolate. The same batch of compost was used for each experimental trial. Also prior to each trial, the pathogenicity of each isolate was tested on the A. bisporus caps to confirm their pathogenicity before the trial. All trials were subjected to the same environmental conditions (temperature and relative humidity) and routine rigid management was maintained in a clean environment to prevent contamination from other pathogens. M. perniciosa isolate WH001 inoculated on A. bisporus strain CCMJ1020 was used as a standard for each trial to detect the effect of variation in growth room conditions on symptom expression.

\subsection{AFLP Analysis}

The AFLP reactions were carried out as described by Vos et al. (1995) [31] with modifications. The adapters and primers used in this study are shown in Table 3 and were purchased from Genset Oligos, France and IBB PAN, Poland. Restriction digestion and adapter ligation were performed simultaneously in a $20 \mu \mathrm{L}$ reaction volume made of $4 \mu \mathrm{L}$ ( $50 \mathrm{ng} / \mu \mathrm{L}$ genomic DNA, $1 \mu \mathrm{L}$ Adapter, $2 \mu \mathrm{L}$ (5 units (U)) HindIII/MseI (New England Biolabs Inc., Ipswich, MA, USA), $2.5 \mu \mathrm{L}$ 10X Reaction buffer, 
$2.5 \mu \mathrm{L} 10 \mathrm{mM}$ ATP, $1 \mu \mathrm{L}$ (1 unit) T4 DNA Ligase (New England Biolabs Inc., Ipswich, MA, USA) and $7 \mu \mathrm{L} \mathrm{H}_{2} \mathrm{O}$. The reaction mixture was centrifuged for $15 \mathrm{~s}$, incubated at $37^{\circ} \mathrm{C}$ for $5 \mathrm{~h}$, held at $8{ }^{\circ} \mathrm{C}$ for $4 \mathrm{~h}$ and stored overnight at $4{ }^{\circ} \mathrm{C}$. The quantity and quality of the digested products were observed using electrophoresis on 1.5\% agarose gels stained with GelRed, visualized and photographed using Bio-Rad Gel Doc XR+ system (Bio-Rad Laboratories Inc., Hercules, CA, USA).

Table 3. Primer pairs used in AFLP analysis.

\begin{tabular}{|c|c|c|c|c|}
\hline No. & & Primer & Sequence $\left(5^{\prime}-3^{\prime}\right)$ & Application \\
\hline 1 & $\mathrm{~F}$ & HindIII 1 & CTC GTA GAC TG CGT ACC & \multirow{4}{*}{ Adaptor } \\
\hline 2 & $\mathrm{R}$ & HindIII 2 & AGC TGG TAC GCA GGT CTA C & \\
\hline 3 & $\mathrm{~F}$ & MseI 1 & AGC TGG TAC GCA GGT CTA C & \\
\hline 4 & $\mathrm{R}$ & MseI 2 & TAC TCA GGA CTC AT & \\
\hline 5 & $\mathrm{~F}$ & HindIII & AGA CTG CGT ACC AGC TTA & Non-selective \\
\hline 6 & $\mathrm{R}$ & MseI & GAT GAG TCC TGA GTA AC & Pre-amplification \\
\hline \multicolumn{4}{|c|}{ Hind III (5 ng/ $\mu \mathrm{L})$} & \\
\hline 7 & $\mathrm{~F}$ & Hind III A & AGA CTG CGT ACC AGC TTA AC & \multirow{8}{*}{ PCR Selective amplification } \\
\hline 8 & $\mathrm{R}$ & Hind III B & AGA CTG CGT ACC AGC TTA AG & \\
\hline 9 & $\mathrm{~F}$ & Hind III C & AGA CTG CGT ACC AGC TTA CA & \\
\hline 10 & $\mathrm{R}$ & Hind III D & AGA CTG CGT ACC AGC TTA CT & \\
\hline 11 & $\mathrm{~F}$ & Hind III E & AGA CTG CGT ACC AGC TTA CC & \\
\hline 12 & $\mathrm{R}$ & Hind III F & AGA CTG CGT ACC AGC TTA CG & \\
\hline 13 & $\mathrm{~F}$ & Hind III G & AGA CTG CGT ACC AGC TTA GC & \\
\hline 14 & $\mathrm{R}$ & Hind III H & AGA CTG CGT ACC AGC TTA GG & \\
\hline \multicolumn{4}{|c|}{ MseI primers (30 ng/ $\mu \mathrm{L})$} & \\
\hline 15 & $\mathrm{~F}$ & FAM mark MseI-1 & GAT GAG TCC TGA GTA ACA A & \multirow{8}{*}{ PCR Selective amplification } \\
\hline 16 & $\mathrm{R}$ & FAM mark MseI-2 & GAT GAG TCC TGA GTA ACA C & \\
\hline 17 & $\mathrm{~F}$ & FAM mark MseI-3 & GAT GAG TCC TGA GTA ACA G & \\
\hline 18 & $\mathrm{R}$ & FAM mark MseI-4 & GAT GAG TCC TGA GTA ACA T & \\
\hline 19 & $\mathrm{~F}$ & FAM mark MseI-5 & GAT GAG TCC TGA GTA ACT A & \\
\hline 20 & $\mathrm{R}$ & FAM mark MseI-6 & GAT GAG TCC TGA GTA ACT C & \\
\hline 21 & $\mathrm{~F}$ & FAM mark MseI-7 & GAT GAG TCC TGA GTA ACT G & \\
\hline 22 & $\mathrm{R}$ & FAM mark MseI-8 & GAT GAG TCC TGA GTA ACT T & \\
\hline
\end{tabular}

$\mathrm{NB}: \mathrm{F}$ = forward primer; $\mathrm{R}$ = reverse primer.

Nonselective PCR pre-amplification was performed on the digested and ligated template DNA using non-selective primer pair HindIII/MseI in a total volume of $25 \mu \mathrm{L}$. The PCR was performed in a T-Personal thermal cycler (Biometra, Göttingen, Germany) with the following settings: $94{ }^{\circ} \mathrm{C}$ for $2 \mathrm{~min}$ followed by 30 cycles of $30 \mathrm{~s}$ at $94{ }^{\circ} \mathrm{C}, 30 \mathrm{~s}$ at $56^{\circ} \mathrm{C}$, and $80 \mathrm{~s}$ at $72{ }^{\circ} \mathrm{C}$. The final thermal cycle was followed by a $5 \mathrm{~min}$ extension at $72{ }^{\circ} \mathrm{C}$ and (hold temperature conserved at $4{ }^{\circ} \mathrm{C}$ for the moment) and stored at $-20^{\circ} \mathrm{C}$ before gel electrophoresis. The PCR products were diluted 20-fold with TE buffer. The selective PCR amplification was performed in $25 \mu \mathrm{L}$ total volume containing eight different primer pairs consisting of HindIII combined with MseI (Table 3). All reactions were carried out in a T-Personal thermal cycler (Biometra, Göttingen, Germany) with the following settings; first-round amplification, $94{ }^{\circ} \mathrm{C}$ for $2 \mathrm{~min}$ followed by 12 cycles of amplification, with a decreasing annealing temperature of $0.7^{\circ} \mathrm{C} / \mathrm{cycle}$ : $94^{\circ} \mathrm{C}$ for $30 \mathrm{~s}$, first annealing for $30 \mathrm{~s}$ at $65^{\circ} \mathrm{C}$ (the annealing temperature was influenced by primers Tm), $72{ }^{\circ} \mathrm{C}$ for $80 \mathrm{~s}$, and next 23 amplification cycles of $94^{\circ} \mathrm{C}$ for $30 \mathrm{~s}, 55^{\circ} \mathrm{C}$ (the annealing temperature was influenced by primers Tm) for $30 \mathrm{~s}$, and $72{ }^{\circ} \mathrm{C}$ for $80 \mathrm{~s}$. The final thermal cycle was followed by the extension of $5 \mathrm{~min}$ at $72{ }^{\circ} \mathrm{C}$. The PCR yields were stored at $4{ }^{\circ} \mathrm{C}$ till subsequent analysis. Five $\mu \mathrm{L}$ of loading buffer (GelT ${ }^{\mathrm{M}}$ Vilber Lourmat, Collégien, France) were added to $25 \mu \mathrm{L}$ of the PCR products. The mixture was loaded on $1 \%$ polyacrylamide gel in $1 \times$ TBE buffer $(89 \mathrm{mM}$ boric acid, $89 \mathrm{mM}$ Tris base, $2 \mathrm{mM}$ EDTA, pH8.0) and run in the Agagel Mini, Biometra electrophoresis system (Biometra, Göttingen, Germany) was run at $200 \mathrm{~V}$ in TBE buffer for $20 \mathrm{~min}$. The gels were stained 
with GelRed (Biotium, Inc., Fremont, CA, USA), visualized and imaged on a UV transilluminator (Vilber Lourmat FLX-20M, Collégien, France). The DNA samples of each isolate were extracted three times from fresh fungal cultures and fingerprinted twice to estimate the reproducibility of the AFLP band patterns. The electrophoretograms were examined using GeneScan ${ }^{\circledR}$ Analysis Software (Applied Biosystems, Inc., Foster City, CA, USA). AFLP markers were physically scored as binary data for the existence or nonexistence of fragments between 70 and $500 \mathrm{bp}$. This binary data obtained was later used to estimate the Jaccard's pairwise similarity coefficients as applied in the FreeTree version 0.9.1.50 program [32]. The unweighted-pair-grouping method with arithmetic average (UPGMA) dendrogram was produced from DNA band patterns using the Nei and Li correlation coefficient [14]. The phylogenetic tree was viewed and edited using NTSYSpc version 2.02 (Exeter Software, Setauket, New York, USA).

\section{Conclusions}

This study showed the variation in virulence and demonstrated the applicability of the AFLP technique to distinguish the genetic variation among M. perniciosa isolates from China. However, there is a need for continuous monitoring of mushroom farms in the various geographical areas in China to collect a large sample population and also compare them with other isolates from different countries for a more detailed genetic analysis, population structure, and evolution of M. perniciosa. Furthermore, identification and development of genetic markers associated with pathogenicity (virulence) will aid in selecting sources of disease resistance and breed A. bisporus with broad resistance to the various pathotypes of M. perniciosa, in order to develop a more effective management strategy to control wet bubble disease in China.

Supplementary Materials: The following are available online at http://www.mdpi.com/2076-0817/8/4/179/s1, Table S1: Conidia production (conidia per $\mathrm{mL}$ ) of 18 isolates of Mycogone perniciosa growing on PDA medium at $25^{\circ} \mathrm{C}$ for 7 days.

Author Contributions: Conceptualization, Y.F.; Funding acquisition, Y.F., B.S., and Y.L.; Writing-original draft, D.L., F.L.S., and Y.F.; Writing-review and editing, D.L., F.L.S and Y.F.; Formal analysis, D.L., Y.D., Y.Y., and Y.F.; Software, D.L., Y.D., Y.Y., and F.L.S.; Methodology, D.L., Y.D., Y.Y., Z.L., and F.L.S.; Resources, D.L. and F.L.S.

Funding: This research was funded by the National Natural Science Foundation of China (no. 31701977); Science and Technology Research "13th Five-Year Plan" Projects of Education Department of Jilin Province ((2016) 191); Changchun Science and Technology Project (no. 15SS11); The Special Fund for Agro-scientific Research in the Public Interest (no. 201503137); The Program of Creation and Utilization of Germplasm of Mushroom Crop of "111" Project (no. D17014); National-level International Joint Research Centre (2017B01011); The International Agrobiological Resources and the Collection of Information about Agro-technic Demands and Agricultural Strategies (2016-X07).

Conflicts of Interest: The authors declare no conflict of interest.

\section{References}

1. Royse, D.J.; Baars, J.; Tan, Q. Current Overview of Mushroom Production in the World. In Edible and Medicinal Mushrooms: Technology and Applications; Diego, C.Z., Pardo-Giménez, A., Eds.; John Wiley \& Sons Ltd.: Hoboken, NJ, USA, 2017; pp. 5-13. [CrossRef]

2. Zhang, Y.; Geng, W.; Shen, Y.; Wang, Y.; Dai, Y.-C. Edible Mushroom Cultivation for Food Security and Rural Development in China: Bio-Innovation, Technological Dissemination and Marketing. Sustainability 2014, 6, 2961-2973. [CrossRef]

3. Fletcher, J.T.; Drakes, G.D.; Talent, C.J.W. The control of wet bubble disease of mushrooms caused by Mycogone perniciosa. Ann. Appl. Biol. 1975, 79, 35-41. [CrossRef]

4. Fletcher, J.T.; Jaffe, B.; Muthumeenakshi, S.; Brown, A.E.; Wright, D.M. Variations in isolates of Mycogone perniciosa and in disease symptoms in Agaricus bisporus. Plant Pathol. 1995, 44, 130-140. [CrossRef]

5. Smith, F.E.V. Three diseases of cultivated mushrooms. Trans. Br. Mycol. Soc. 1924, 10, 81-97, IN4-IN5. [CrossRef]

6. Fan, J.; Zhang, H.; Zhang, Z.; Gong, P.; He, W.A.; Zhu, Y. Integrated Control Technology of Mycogone perniciosa Magn. of Agaricus bisporus. North. Hortic. 2012, 6, 168-170. 
7. Fu, Y.; Wang, X.; Li, D.; Liu, Y.; Song, B.; Zhang, C.; Wang, Q.; Chen, M.; Zhang, Z.; Li, Y. Identification of Resistance to Wet Bubble Disease and Genetic Diversity in Wild and Cultivated Strains of Agaricus bisporus. Int. J. Mol. Sci. 2016, 17, 1568. [CrossRef]

8. Wen, Z.; Wang, Y.; Liu, X.; Xie, B. Population differentiation of Mycogone perniciosa in Fujian, China. Mycosystema 2010, 29, 329-334.

9. Zhou, C.; Li, D.; Chen, L.; Li, Y. Genetic Diversity Analysis of Mycogone perniciosa Causing Wet Bubble Disease of Agaricus bisporus in China Using SRAP. J. Phytopathol. 2016, 164, 271-275. [CrossRef]

10. Wang, W.; Li, X.; Chen, B.; Wang, S.; Li, C.; Wen, Z. Analysis of Genetic Diversity and Development of SCAR Markers in a Mycogone perniciosa Population. Curr. Microbiol. 2016, 73, 9-14. [CrossRef]

11. Garcia-Mas, J.; Oliver, M.; Gómez-Paniagua, H.; de Vicente, M.C. Comparing AFLP, RAPD and RFLP markers for measuring genetic diversity in melon. Theor. Appl. Genet. 2000, 101, 860-864. [CrossRef]

12. Li, D.; Sossah, F.L.; Sun, L.; Fu, Y.; Li, Y. Genome Analysis of Hypomyces perniciosus, the Causal Agent of Wet Bubble Disease of Button Mushroom (Agaricus bisporus). Genes 2019, 10, 417. [CrossRef] [PubMed]

13. Zhang, C.L.; Xu, J.Z.; Kakishima, M.; Li, Y. First Report of Wet Bubble Disease Caused by Hypomyces perniciosus on Pleurotus citrinopileatus in China. Plant Dis. 2017, 101, 1321. [CrossRef]

14. Zhang, C.; Kakishima, M.; Xu, J.; Wang, Q.; Li, Y. The effect of Hypomyces perniciosus on the mycelia and basidiomes of Agaricus bisporus. Microbiology 2017, 163, 1273-1282. [CrossRef] [PubMed]

15. Khot, P.D.; Fredricks, D.N.; Ko, D. Sequencing and analysis of fungal rRNA operons for development of broad-range fungal PCR assays. Appl. Environ. Microbiol. 2009, 75, 1559. [CrossRef] [PubMed]

16. PÉRez-Sierra, A.N.A.; Henricot, B. Identification of fungal species beyond morphology. Mycologist 2002, 16, 42-46. [CrossRef]

17. Tessmann, D.J.; Charudattan, R.; Preston, J.F. Variability in aggressiveness, cultural characteristics, cercosporin production and fatty acid profile of Cercospora piaropi, a biocontrol agent of water hyacinth. Plant Pathol. 2008, 57, 957-966. [CrossRef]

18. Rokni, N.; Goltapeh, E.M. Tolerance to dry bubble disease (Lecanicillium fungicola) in Iranian wild germplasm of button mushroom (Agaricus bisporus). Mycoscience 2019, 60, 125-131. [CrossRef]

19. Fox, E.M.; Howlett, B.J. Secondary metabolism: regulation and role in fungal biology. Curr. Opin. Microbiol. 2008, 11, 481-487. [CrossRef]

20. Frézal, L.; Jacqua, G.; Neema, C. Adaptation of a Fungal Pathogen to Host Quantitative Resistance. Front. Plant Sci. 2018, 9, 1554. [CrossRef]

21. Begerow, D.; Nilsson, H.; Unterseher, M.; Maier, W. Current state and perspectives of fungal DNA barcoding and rapid identification procedures. Appl. Microbiol. Biotechnol. 2010, 87, 99-108. [CrossRef]

22. Shang, Y.; Xiao, G.; Zheng, P.; Cen, K.; Zhan, S.; Wang, C. Divergent and Convergent Evolution of Fungal Pathogenicity. Genome Biol. Evol. 2016, 8, 1374-1387. [CrossRef] [PubMed]

23. Skrbinšek, T.; Jelenčič, M.; Waits, L.P.; Potočnik, H.; Kos, I.; Trontelj, P. Using a reference population yardstick to calibrate and compare genetic diversity reported in different studies: An example from the brown bear. Heredity 2012, 109, 299. [CrossRef] [PubMed]

24. Radišek, S.; Jakše, J.; Simončič, A.; Javornik, B. Characterization of Verticillium albo-atrum Field Isolates Using Pathogenicity Data and AFLP Analysis. Plant Dis. 2003, 87, 633-638. [CrossRef]

25. Staats, M.; van Baarlen, P.; van Kan, J.A. Molecular phylogeny of the plant pathogenic genus Botrytis and the evolution of host specificity. Mol. Biol. Evol. 2005, 22, 333-346. [CrossRef] [PubMed]

26. Nabi, A.; Shah, M.-U.-D.; Padder, B.A.; Dar, M.S.; Ahmad, M. Morpho-cultural, pathological and molecular variability in Thyrostroma carpophilum causing shot hole of stone fruits in India. Eur. J. Plant Pathol. 2018, 151, 613-627. [CrossRef]

27. Uppal, A.K.; El Hadrami, A.; Adam, L.R.; Daayf, F.; Tenuta, M. Pathogenic variability of Verticillium dahliae isolates from potato fields in Manitoba and screening of bacteria for their biocontrol. Can. J. Plant Pathol. 2007, 29, 141-152. [CrossRef]

28. White, T.J.; Bruns, T.; Lee, S.; Taylor, J.; White, T.J.; Bruns, T.D.; Lee, S.B.; Taylor, J.W. Amplification and direct seqencing of fungal ribosomal RNA genes for phylogenetics. PCR Protoc. Guide Methods Appl. 1990, 315-322. [CrossRef]

29. Tamura, K.; Nei, M. Estimation of the number of nucleotide substitutions in the control region of mitochondrial DNA in humans and chimpanzees. Mol. Biol. Evolut. 1993, 10, 512-526. [CrossRef] 
30. Kumar, S.; Stecher, G.; Li, M.; Knyaz, C.; Tamura, K. MEGA X: Molecular Evolutionary Genetics Analysis across Computing Platform. Mol. Biol. Evolut. 2018, 35, 1547-1549. [CrossRef]

31. Vos, P.; Hogers, R.; Bleeker, M.; Reijans, M.; van de Lee, T.; Hornes, M.; Frijters, A.; Pot, J.; Peleman, J.; Kuiper, M.; et al. AFLP: A new technique for DNA fingerprinting. Nucleic Acids Res. 1995, 23, 4407-4414. [CrossRef]

32. Pavlícek, A.; Hrdá, S.; Flegr, J. Free-Tree-freeware program for construction of phylogenetic trees on the basis of distance data and bootstrap/jackknife analysis of the tree robustness. Application in the RAPD analysis of genus Frenkelia. Folia Biol. 1999, 45, 97-99.

(C) 2019 by the authors. Licensee MDPI, Basel, Switzerland. This article is an open access article distributed under the terms and conditions of the Creative Commons Attribution (CC BY) license (http://creativecommons.org/licenses/by/4.0/). 